\title{
MODELAGEM, SIMULAÇÃO E ANÁLISE DA SECAGEM DE ARROZ EM OPERAÇÃO PERIÓDICA
}

\author{
R. O. DEFENDI ${ }^{1}$, R. O. da SILVA ${ }^{1}$, P. R. PARAÍSO ${ }^{1}$ e L. M. de M. JORGE ${ }^{1}$ \\ ${ }^{1}$ Universidade Estadual de Maringá, Departamento de Engenharia Química \\ E-mail para contato: rafael.defendi@hotmail.com / lmmj@deq.uem.br
}

\begin{abstract}
RESUMO - O objetivo deste trabalho foi avaliar teoricamente as vantagens da secagem periódica de arroz em leito fixo em relação à secagem convencional. $\mathrm{O}$ processo de secagem é necessário para se obter teores de umidades adequados ao armazenamento de grãos. A operação periódica pode ser uma alternativa para reduzir os gastos energéticos envolvidos no processo de secagem. Nesta operação a temperatura ou a velocidade do ar é modulada continuamente em certa frequência e amplitude. Uma vez que as taxas de secagem não variam linearmente com a temperatura, a operação periódica pode ser mais vantajosa em relação à convencional, realizada a temperatura e vazão de ar de secagem constantes. O modelo matemático do secador foi resolvido numericamente o os resultados apontaram que as taxas de secagem são maiores para secagem em operação periódica em relação aos resultados simulados em operação convencional, para o mesmo consumo energético.
\end{abstract}

\section{INTRODUÇÃO}

De acordo com dados da Conab, a produção brasileira de arroz durante o ano safra 2012/2013 foi próxima a 12 milhões de toneladas. Segundo projeções feitas pelo Ministério da Agricultura Pecuária e Abastecimento, haverá um aumento em $11,1 \%$ na produção brasileira de arroz nos próximos 10 anos (2022/2023). Este valor equivale à projeção de consumo brasileira nestes próximos 10 anos. Para garantir uma boa qualidade destes grãos durante sua cadeia produtiva é necessário que se faça uma armazenagem ideal que evite perdas deste material.

O armazenamento de grãos é um processo necessário, uma vez que sua produção é periódica e as demandas das indústrias e do comércio são ininterruptas (Puzzi, 2000). Uma colheita realizada em dois meses pode ser consumida durante um ou mais anos. Contudo, muitos fatores podem prejudicar a qualidade destes grãos enquanto eles estão armazenados. De acordo com Puzzi (2000), estes fatores podem ser um agente físico (temperatura, teor de umidade, danos mecânicos) ou um agente biológico (microorganismos, insetos, fungos). Este autor ainda ressalta que é importante controlar e minimizar os efeitos provenientes destes fatores para garantir a qualidade e a composição química (carboidratos, gorduras, proteínas, fibras, minerais e vitaminas) destes grãos.

Observa-se que o teor de umidade é o fator predominante que controla a qualidade do grão estocado (Puzzi, 2000). Em baixos valores de umidade, as reações enzimáticas são reduzidas como 


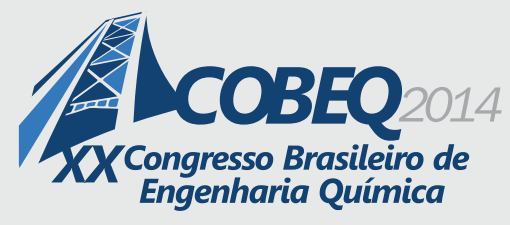

19 a 22 de outubro de 2014

Florianópolis/SC

também as taxas de respiração inerentes ao metabolismo do grão que podem levar o material à podridão. O teor de umidade pode ser controlado pelo processo de secagem. Neste contexto, é importante secar grãos colhidos até níveis seguros de umidade para se alcançar um armazenamento ideal sem riscos de deterioração dos grãos (Puzzi, 2000; Martins et al., 2002). O nível seguro de teor de umidade para se armazenar o arroz durante um ano é de 13\% em base úmida e para períodos superiores a um ano é de 12\% em base úmida (Lazzari, 1993).

Muitos produtores brasileiros usam armazéns para estocar grãos e utilizam as condições naturais do ambiente para secar os grãos enquanto estes ainda estão na lavoura (Martins et al., 2002). Embora as condições do clima brasileiro sejam favoráveis, esta prática de secagem natural não tem sido eficiente para evitar perdas tanto quantitativas quanto qualitativas do material armazenado (Martins et al., 2002). Por outro lado, a secagem forçada com ar quente pode garantir as condições ideais de armazenamento, possibilitando que o grão chegue a níveis de umidade satisfatórios para evitar estas perdas. Embora o processo de secagem com ar quente seja muito utilizado pelas indústrias de grãos, este processo encarece os custos de produção devido a grande demanda de energia necessária para movimentar e aquecer o ar de secagem (Biagi et al., 2002). De acordo com Silva et al. (2000), a secagem em temperaturas altas pode consumir $60 \%$ ou mais do total de energia usada na produção de produtos agrícolas.

Neste contexto, este trabalho visa estudar uma alternativa para reduzir estes custos por meio da operação periódica, a qual pode potencializar os transportes de massa e de energia envolvidos no processo proporcionando uma redução no consumo energético. A operação periódica consiste numa contínua modulação das condições operacionais (como a temperatura e a velocidade do ar) numa específica frequência e amplitude. Como as taxas de secagem não são linearmente dependentes da temperatura do ar, a operação periódica pode alcançar uma eficiência maior em comparação a operação convencional (realizada com temperatura e vazão do ar constantes) em processos em que ambas as operações são tomadas com o mesmo gasto energético e tempo de secagem.

O estudo da secagem periódica de grãos é recente e há poucas referências sobre este assunto atualmente. Contudo, alguns autores estudaram a operação periódica em reatores químicos onde observaram que a modulação das condições dos reagentes pode melhorar o rendimento do reator (Silveston e Hanika, 2004; Lange et al., 1999; Rouge et al., 2001; Tukac et al., 2003; Tukac et al., 2007). De acordo com Silveston e Hanika (2004), a operação periódica em reatores trifásicos pode mudar a seletividade e aumentar tanto a conversão quanto o rendimento. Estes autores ainda acrescentam que as taxas de reação são potencializadas sob a periódica interrupção do fluxo para leitos gotejantes.

Lange et al. (1999) estudaram a operação periódica num reator de leito gotejante. Eles observaram que houve um aumento no tempo médio de conversão de $\alpha$-metilestireno para reações conduzidas com modulação periódica do fluxo dos reagentes dependendo dos parâmetros envolvidos na operação. Foi observado que a operação periódica proporcionou um melhor controle e um aumento no rendimento do reator. Rouge et al. (2001) estudaram a desidratação do isopropanol em propeno em operação periódica. Os resultados deste trabalho apontaram que o rendimento do reator em operação periódica aumentou em comparação com o rendimento obtido em operação realizada com as 
condições em regime permanente.

Outro estudo da operação periódica em reatores de leito gotejante foi feita por Tukac et al. (2003). Neste trabalho, foi estudada a remoção de fenol de soluções aquosas a partir da oxidação num catalisador de carvão ativado em operação periódica. Foi possível atingir uma conversão de fenol $10 \%$ maior em comparação com as condições em regime permanente. Tukac et al. (2007) estudaram a hidrogenação do estireno em reatores de leito gotejante operando tanto periodicamente com a modulação da taxa de alimentação da mistura de reação quanto em regime permanente. Neste estudo, observou-se que a operação periódica proporcionou um aumento na produtividade em $30 \%$ da hidrogenação do estireno em comparação com a operação em regime permanente.

Na secagem de grãos, Romero et al. (2010) estudaram a secagem periódica de soja em leito profundo por meio de um modelo heterogêneo a duas fases. Neste estudo, estes autores observaram que a operação periódica pode melhorar o rendimento do secador e também reduzir o consumo energético em comparação à operação convencional.

Neste contexto, o objetivo deste trabalho foi efetuar a modelagem, a simulação e a análise das duas formas de secagem: a convencional e a periódica, destacando-se as vantagens e limitações desta nova modalidade na secagem de arroz em camada delgada. As simulações foram realizadas em condições de mesmo gasto energético e mesmo tempo de secagem para ambas as operações por meio de um modelo matemático baseado em dados cinéticos de secagem de arroz obtidos em camada delgada.

\section{METODOLOGIA}

\subsection{Modelo Matemático}

O modelo utilizado para simular a secagem de arroz em camada delgada, foi o modelo proposto por Thompson et al. (1968):

$$
t=A \cdot \ln (M R)+B \cdot(\ln (M R))^{2}
$$

Onde t é o tempo, A e B são os parâmetros do modelo e RM é a razão entre as seguintes umidades:

$$
M R=\frac{M-M_{e}}{M_{0}-M_{e}}
$$

Onde $\mathrm{M}$ é o teor de umidade do arroz em base seca, $\mathrm{M}_{\mathrm{e}}$ é o teor de umidade de equilibro do arroz também em base seca e $\mathrm{M}_{0}$ é o teor de umidade inicial do arroz. Os valores dos parâmetros $\mathrm{A}$ e B da Equação 1 foram ajustados por Mata (1992) para a secagem de arroz em camada fina conforme segue abaixo:

$$
A=-2445,06+82,79 \cdot T-1,023 \cdot T^{2}+0,004267 \cdot T^{3}
$$




$$
B=-449,68+14,52 \cdot T-0,182 \cdot T^{2}+0,000756 \cdot T^{3}
$$

Onde T é a temperatura do ar de secagem dada em ${ }^{\circ} \mathrm{C}$. Para estes valores dos parâmetros, a unidade do tempo na Equação 1 é dada em minutos. O modelo (Equação 1) foi resolvido discretizando sua equação em 200 divisões no tempo, resultando assim num sistema de equações algébricas. Nas simulações em operação periódica, os valores dos parâmetros mudam para cada valor de temperatura do ar. Assim, em cada ponto discretizado, o valor da umidade inicial foi tomado como o valor da umidade do arroz no ponto anterior e o valor do tempo em cada ponto foi tomado como o valor do intervalo entre dois pontos. Essa metodologia equivale em se iniciar o processo de secagem em cada ponto discretizado partindo das condições de umidade do ponto anterior.

\subsection{Simulação da Operação Periódica e Convencional}

Nas simulações em operação periódica, foi modulada a temperatura do ar num formato senoidal como apresentado na Figura 1. Para cada simulação em operação periódica, uma simulação em operação convencional foi realizada com a temperatura do ar mantida constante no valor igual à média da temperatura do ar da respectiva operação periódica para garantir que ambas as operações fossem simuladas com o mesmo consumo energético referente ao aquecimento do ar. A expressão usada para o cálculo desse consumo energético está apresentada abaixo:

$$
E=G g \cdot \int_{0}^{t} c p_{a r} \cdot T \cdot d t
$$

Onde E é o consumo energético, Gg é a vazão mássica de ar e $\mathrm{cp}_{\mathrm{ar}}$ é o calor específico do ar. O valor da temperatura média da operação periódica, cujo valor equivale a temperatura constante em operação convencional foi calculado pela seguinte equação:

$$
\bar{T}=\frac{\int T \cdot d t}{\int d t}
$$

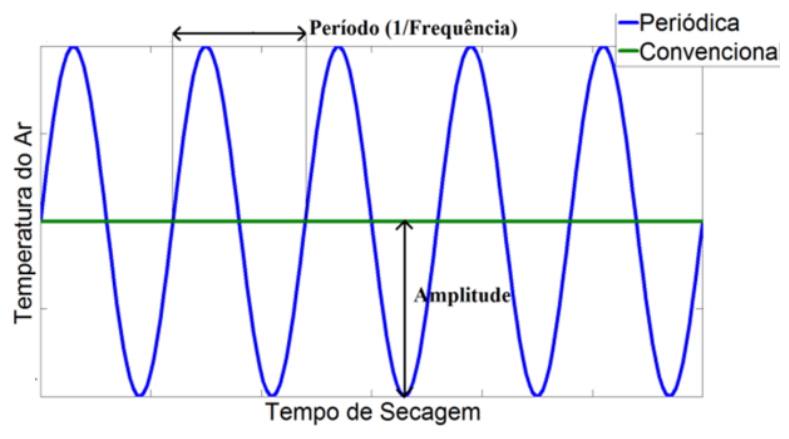

Figura 1 - Modulação da Temperatura do Ar

A equação usada para modular a temperatura do ar em operação periódica foi:

$$
T_{p}=\operatorname{Amp} \cdot \operatorname{sen}(\text { fr.t. } 2 \pi)+T_{c}
$$


Onde $\mathrm{T}_{\mathrm{p}}$ é a temperatura do ar em operação periódica, Amp é a amplitude em ${ }^{\circ} \mathrm{C}$, fr é a frequência em s${ }^{-1}$ e $T_{c}$ é a temperatura do ar em operação convencional. As simulações foram realizadas para períodos de 6 a 60 minutos e amplitudes de 10 a $30{ }^{\circ} \mathrm{C}$. O tempo de simulação foi igual para ambas as operações. A umidade inicial do arroz foi tomada com o valor de 0,18 em base seca e o ar de secagem foi considerado sem umidade. Nessas condições, a umidade de equilíbrio do arroz foi considerada nula.

\section{RESULTADOS E DISCUSSÕES}

Observou-se das simulações que a modulação da temperatura do ar pode aumentar o rendimento da secagem, aumentando as taxas de secagem em comparação à operação convencional realizada com o mesmo consumo energético. A Figura 2 apresenta o perfil de umidade do arroz ao longo da secagem para diferentes valores de amplitude da modulação da temperatura durante um tempo de secagem de uma hora. Deste gráfico, verifica-se que por meio da operação periódica é possível atingir níveis de teor de umidade de arroz menores em comparação aos níveis em operação convencional, o que aponta um aumento nas taxas de secagem. Observa-se que quanto maior o valor da amplitude, maiores são os valores dos picos da temperatura do ar, o que proporciona um aumento nas taxas de secagem favorecendo a operação periódica.

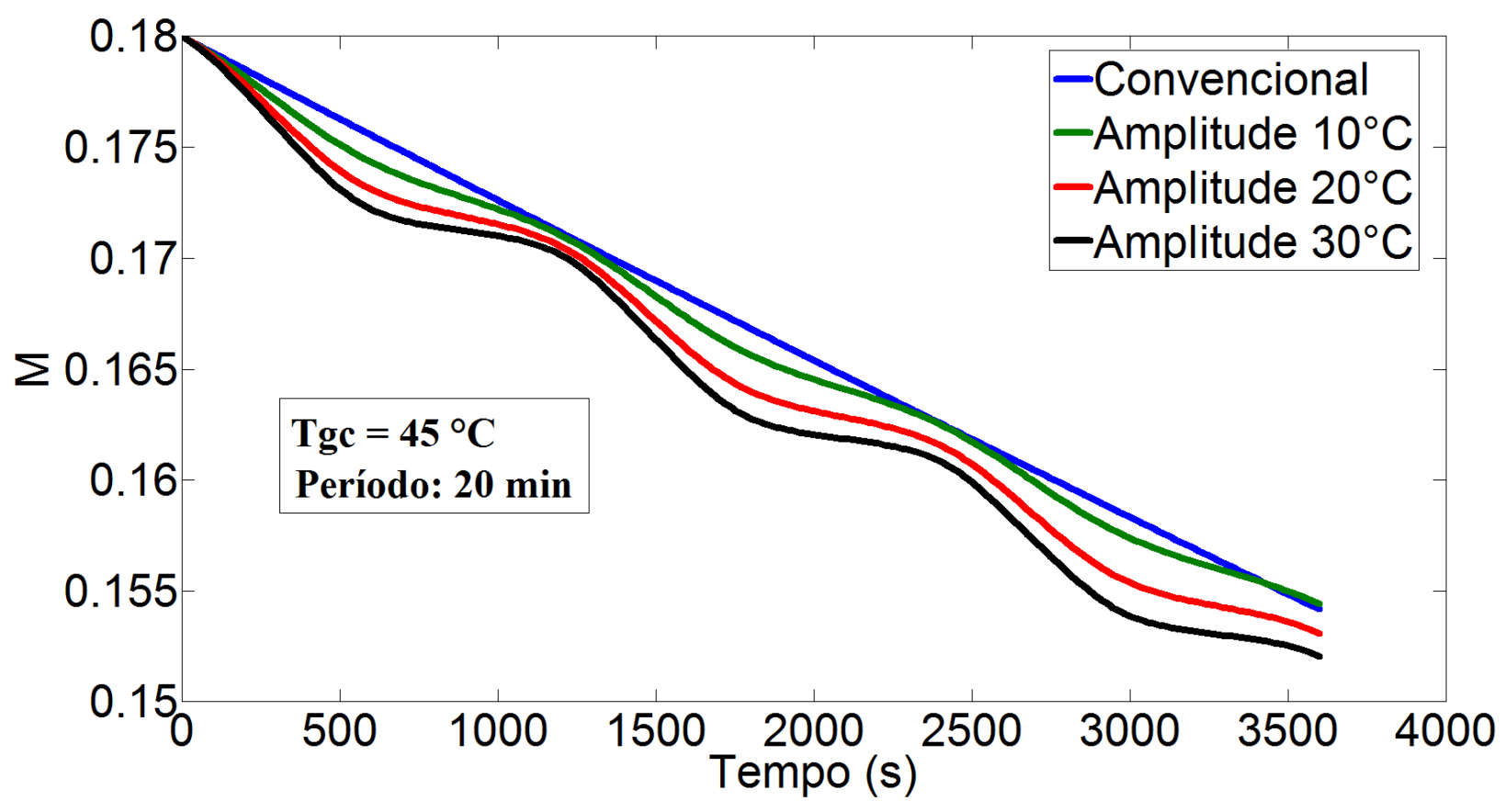

Figura 2 - Perfil de Umidade do Arroz Para Diferentes Amplitudes

Outro fato interessante a ser ressaltado é que a operação periódica é mais vantajosa apenas nas etapas iniciais da secagem dependendo da amplitude da modulação da temperatura do ar como apresenta a Figura 3, a qual ilustra o perfil de umidade do arroz para uma secagem de duas horas. 


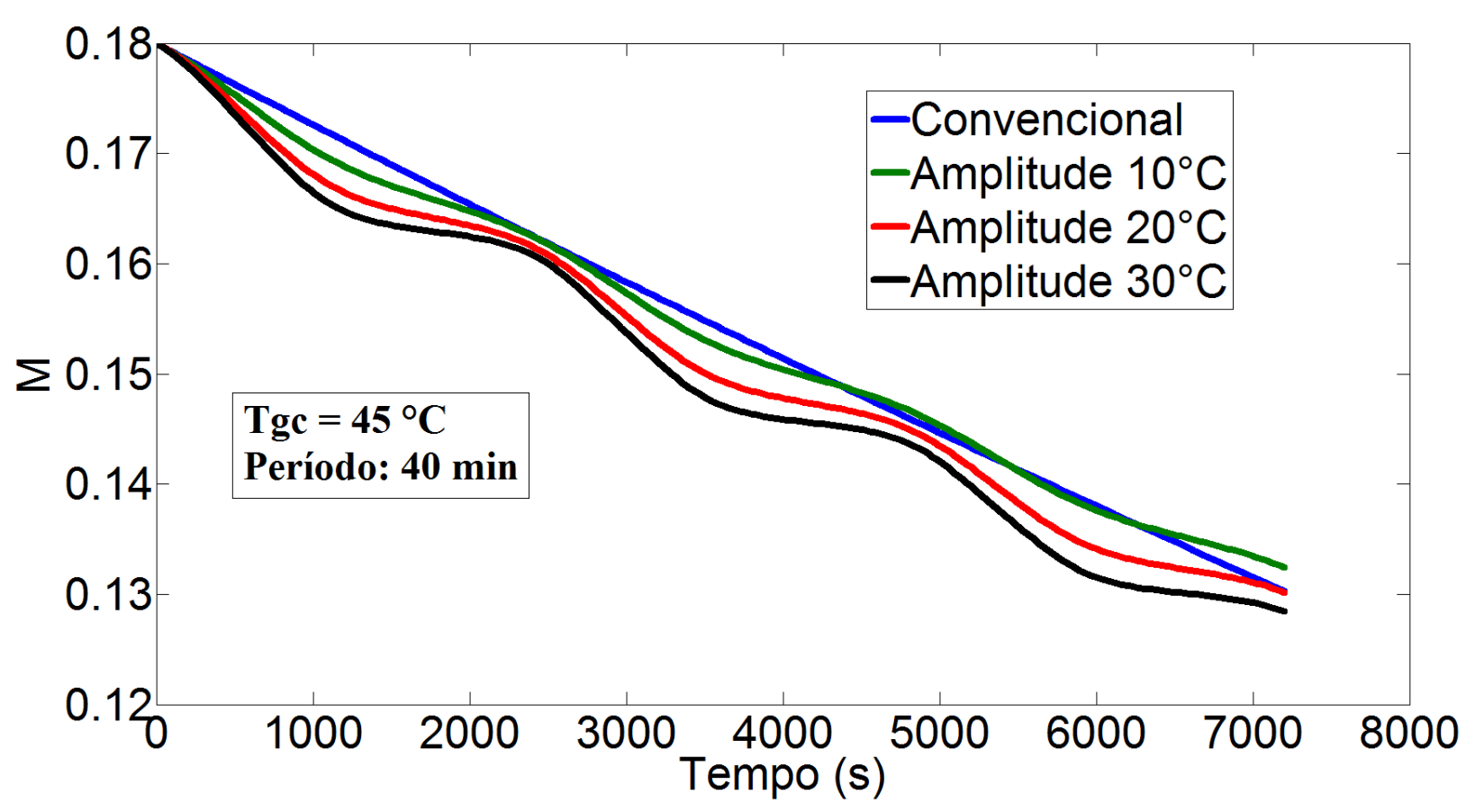

Figura 3 - Perfil de Umidade do Arroz Para Uma Secagem de 2 Horas

Observa-se da Figura 3 que conforme o progresso do tempo de secagem, o nível do teor de umidade do arroz tende a se aproximar ou até mesmo atingir níveis maiores que o nível do teor de umidade em operação convencional. É interessante comparar os perfis nos términos de uma oscilação completa, que para a Figura 3 ocorrem em 40, 80 e 120 minutos, pois o período de cada oscilação equivale a 40 minutos. Nestes pontos, o consumo energético referente ao aquecimento do ar é o mesmo para ambas as operações, periódica e convencional. Neste contexto, observa-se deste gráfico que nestes pontos os níveis da umidade do arroz começam a se aproximar dos níveis em operação convencional conforme o progresso do tempo. Assim, estes resultados indicam que a operação periódica de arroz em cama fina é favorável apenas nas etapas iniciais da secagem dependendo da amplitude das oscilações, uma vez que na amplitude de $30^{\circ} \mathrm{C}$ a operação periódica foi favorável durante todo o processo de secagem.

Além disso, analisou-se o impacto do valor do período inerente a modulação da temperatura do ar no perfil de umidade de arroz para valores de amplitudes semelhantes como apresenta a Figura 4. Desta Figura, é possível verificar que para iguais valores de amplitudes, mas para diferentes valores de períodos o nível do teor de umidade do arroz foi o mesmo para as diferentes operações periódicas. No final da secagem, o consumo energético para todas as operações periódicas é o mesmo. Assim, o valor do período não impactou nas taxas de secagem nos instantes em que o consumo energético é o mesmo, não impactando assim no rendimento do aquecedor. Contudo, altos valores de período aumentam as taxas de secagem no início do processo, pois o tempo em que o material fica em contato com o ar em altas temperaturas é maior no início, mas depois esta vantagem inicial é descompensada nos instantes finais da secagem, onde o ar fica a baixas temperaturas pelo mesmo tempo. 


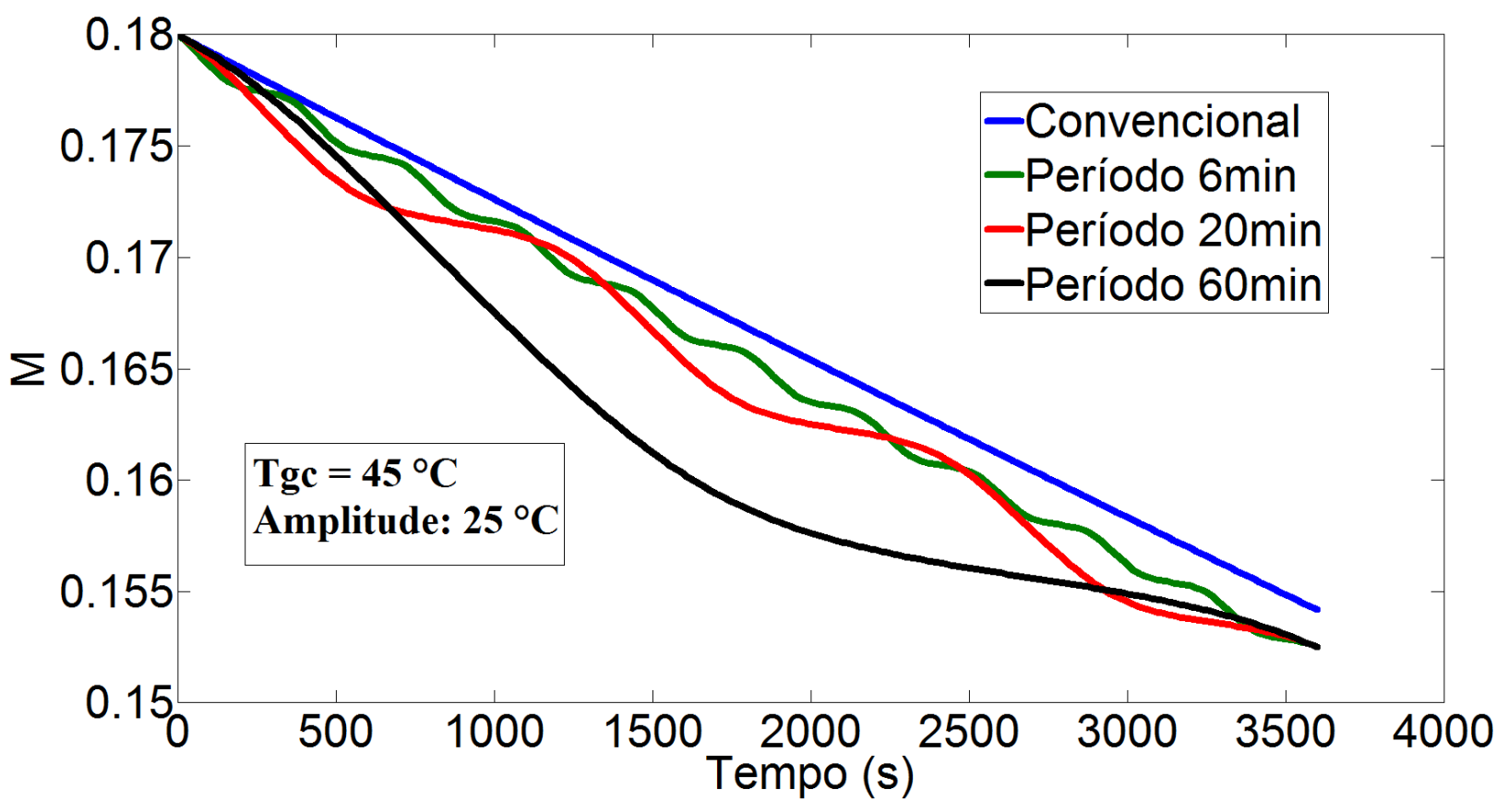

Figura 4 - Perfil de Umidade do Arroz Para Diferentes Períodos

\section{CONCLUSÃO}

$\mathrm{O}$ uso da operação periódica na secagem de arroz em camada fina revelou-se ser uma alternativa para reduzir os gastos do processo em comparação à operação convencional. A modulação da temperatura do ar permitiu atingir níveis menores de umidade do material em comparação a resultados com a temperatura do ar constante em simulações onde ambas as operações foram realizadas com o mesmo consumo energético inerente ao aquecimento do ar. Estes resultados indicam que para se atingir um determinado nível seguro de umidade para armazenamento, a operação periódica pode demandar menos energia para o mesmo tempo de operação. Além disso, observou-se que quanto maior a amplitude de modulação da temperatura, maiores são as taxas de secagem devido aos altos picos de temperatura atingidos, favorecendo assim a operação periódica.

\section{AGRADECIMENTOS}

O presente trabalho foi realizado com o apoio do Conselho Nacional de Desenvolvimento Científico e Tecnológico - $\mathrm{CNPq}$ - e com o apoio da Coordenação de Aperfeiçoamento de Pessoal de Nível Superior - CAPES - Brasil.

\section{REFERÊNCIAS}

BIAGI, J. D.; BERTOL, R.; CARNEIRO, M. C. Secagem de grãos para unidades centrais de armazenamento. In Armazenagem de Grãos. LORINI, I.; MIIKE, L. H.; SCUSSEL, V. M.; Campinas: Instituto Bio Geneziz, 2002; 289-307. 
LANGE, R.; GUTSCHE, R.; HANIKA, J. Forced Periodic Operation of a Trickle-Bed Reactor. Chemical Engineering Science, v. 54, p. 2569-2573, 1999.

LAZZARI, F. A. Umidade, fungos e micotoxinas na qualidade de sementes, grãos e rações. Curitiba: Ed. Do Autor, 1993.

MARTINS, R. M.; FRANCO, J. B. da R.; OLIVEIRA, A. V.; ANGONESE, C. Armazéns para propriedade familiar. In Armazenagem de Grãos. LORINI, I.; MIIKE, L. H.; SCUSSEL, V. M.; Campinas: Instituto Bio Genezizs, 2002; 117-155.

MATA, M. E. R. M. C. Secagem e Armazenagem de Produtos Agrícolas. Campina Grande: Núcleo de Tecnologia em Armazenagem, Universidade Federal da Paraíba, 1992.

PUZZI, D. Abastecimento e Armazenagem de Grãos. Campinas: Instituto Campineiro de Ensino Agrícola, 2000.

ROMERO, J. A. da S.; OMOTO, E. S.; CONCEIÇÃO, W. A. dos S.; COUTINHO, M. R.; PARAÍSO, P. R.; JORGE, L. M. M. Estudo da secagem de soja em operação periódica. COBEQ XVIII Congresso Brasileiro de Engenharia Química, Foz do Iguaçú, Brasil, Setembro, 2010.

ROUGE, A.; SPOETZL, B.; GEBAUER, K.; SCHENK, R.; RENKEN, A. Microchannel reactors for fast periodic operation: the catalytic dehydration of isopropanol. Chemical Engineering Science, v. 56, p. 1419-1427, 2001.

SILVA, J. S.; AFONSO, A. D. L.; DONZELlES, S. M. L. Secagem e Secadores. In Secagem e Armazenagem de Produtos Agrícolas. SILVA, J. S. Viçosa: Aprenda Fácil, 2000; 107-138.

SILVESTON, P. L.; HANIKA, J. Periodic Operation of Three-Phase Catalytic Reactors. The Canadian Journal of Chemical Engineering, v. 82, p. 1105-1142, 2004.

THOMPSON, T.L.; PEART, R.M.; FOSTER, G.H. Mathematical Simulation of Corn Drying - A New Model. Transactions of the ASAE, v. 11 (4), p. 582-586, 1968.

TUKAC, V.; HANIKA, J.; CHYBA, V. Periodic state of wet oxidation in trickle-bed reactor. Catalysis Today, v. 79-80, p. 427-431, 2003.

TUKAC, V.; SIMICKOVÁ, M.; CHYBA, V.; LEDERER, J.; KOLENA, J.; HANIKA, J.; JIRICNY, V.; STANEK, V.; STAVÁREK, P. The behavior of pilot trickle-bed reactor under periodic operation. Chemical Engineering Science, v. 62, p. 4891-4895, 2007. 